\title{
Cost effectiveness of a multi-stage return to work program for workers on sick leave due to low back pain, design of a population based controlled trial [ISRCTN60233560]
}

\author{
Ivan A Steenstra1,2,3,4, Johannes R Anema1,2,3,4, Paulien M Bongers ${ }^{1,3,4}$, \\ Henrica CW de Vet ${ }^{1}$ and Willem van Mechelen*1,2,4
} \begin{abstract}
Medicine VU University Medical Center, Amsterdam, The Netherlands, ${ }^{3}$ TNO Work and Employment, The Netherlands and ${ }^{4}$ Body@Work, Research Center Physical Activity, Work and Health, TNO-VU, The Netherlands

Email: Ivan A Steenstra - i.steenstra.emgo@med.vu.nl; Johannes R Anema - h.anema@arbeid.tno.nl;

Paulien M Bongers - p.bongers@arbeid.tno.nl; Henrica CW de Vet - hcw.de_vet.emgo@med.vu.nl; Willem van

Mechelen* - w.vanmechelen@vumc.nl

* Corresponding author
\end{abstract}

Address: ${ }^{1}$ Institute for Research in Extramural Medicine, VU University Medical Center, Amsterdam, The Netherlands, ${ }^{2}$ Department of Social

Published: 2I November 2003

BMC Musculoskeletal Disorders 2003, 4:26

This article is available from: http://www.biomedcentral.com/I47/-2474/4/26

(C) 2003 Steenstra et al; licensee BioMed Central Ltd. This is an Open Access article: verbatim copying and redistribution of this article are permitted in all media for any purpose, provided this notice is preserved along with the article's original URL.
Received: 24 June 2003

Accepted: 21 November 2003

\begin{abstract}
Background: To describe the design of a population based randomized controlled trial (RCT), including a cost-effectiveness analysis, comparing participative ergonomics interventions between 2-8 weeks of sick leave and Graded Activity after 8 weeks of sick leave with usual care, in occupational back pain management.
\end{abstract}

\section{Methods:}

Discussion: The combination of these interventions has been subject of earlier research in Canada. The results of the current RCT will: I. crossvalidate the Canadian findings in an different sociocultural environment; 2 . add to the cost-effectiveness on treatment options for workers in the sub acute phase of low back pain. Results might lead to alterations of existing (inter)national guidelines.

\section{Background}

Arguments for publishing a design

In this article, we describe the design of an RCT and costeffectiveness analysis of a multi-stage protocol roughly consisting of two interventions: an occupational intervention and a Graded Activity intervention. Publishing the design and rationale of this randomized controlled trial (RCT), including a cost-effectiveness analysis, before the results are available, has some important benefits. It gives the author a chance to elaborate on the content of the interventions [1]. This extensive information gives caregivers more insight in the practical application of the interventions in the study, which contributes to an easier implementation of the interventions in practice. It can be a helpful document for both researchers contemplating intervention or evaluation studies of LBP themselves as well as for research-users who try to make an informed choice between different return to work strategies. Furthermore, it offers the opportunity to consider the methodological quality of the study more critically, irrespective 
of the results. Usually methodological deficiencies are examined critically in case results are not in line with the expectations of the researcher or reader, but when results meet the expectations, methodological strengths and weaknesses will receive less attention. Finally, it may prevent publication bias. Trials that lead to adverse or negative results are less likely to be submitted for publication $[2,3]$. This can be avoided by publishing a priori the design of a study. Not only will the researcher be more inclined to publish the results, but in any case, data can still be requested from the researcher for inclusion in a systematic review.

\section{Low back pain}

Back pain is a common problem in Western societies. It causes major disability and considerable financial costs. Most costs (approx. 93\%) are caused however by absenteeism from work in a limited number of cases [4]. Total costs estimates vary from 0.28 to $1.7 \%$ of the Gross National Product, depending on the method used [5]. Most costs are caused by patients who are of work for more than 6 months [6,7]. Based on the report of the Quebec Task Force on Spinal Disorders [8] that recommended early intervention to reduce chronicity, a model has been developed by researchers at Sherbrooke University, Canada. Aim of this model was to treat sub-acute occupational back pain and to prevent transition to the chronic phase. The model has been evaluated in Canada in a population-based, randomized clinical trial [9] where it has proven to be an effective tool in return to work. Because of differences in legislation these results can not automatically be transferred to the Dutch situation.

\section{Sick leave in the Netherlands}

Sick leave is covered by a Law that regulates salary payment during sick leave and by the Working conditions law, which were implemented from 1994 to 2002. These laws were supplemented by several other acts resulting in the following consequences: 1 . the employer has to pay at least $70 \%$ of wages for the first full year of sick leave; 2 . an inventory of work-related health risks and a contract with an occupational health service is obligatory for all companies. The most important supplement to these laws has been the implementation of the "Improved Gatekeeper Law" which became effective on April 1, 2002. According to this law payment by the employer for an additional year of wages during sick leave can be mandatory, in case the employer has not put enough effort into vocational rehabilitation of the worker during the first year of sick leave. On the other hand a worker can loose some of his employment protection in case the worker has not put enough effort into work resumption. Central working agreements between workers and employers ensure payment of $100 \%$ of wages in most cases during the first year of sick leave, regardless the above mentioned laws.
After the employers first year of sick leave "risk" period, a claim for disability benefits can be made. A national organisation assesses the working capacity of the injured worker. Based on this assessment a (partial) allowance can be rewarded. The magnitude of their allowance is based on the loss of earning capacity. Workers can be partial on disability benefit and get additional earnings from regular work or from unemployment benefits. In these cases earnings influence the magnitude of disability allowance.

Health care costs are covered by the National Health Insurance or by a private insurance for workers above a certain income threshold ( $€ 31.750$ in 2003). Vocational rehabilitation costs paid for by the employer are covered by a tax reduction scheme for the employer and can be eligible also for a subsidy, in case costly work adjustments have to be made to keep the worker on the job.

\section{Methods}

\section{Organisation of the study}

The study is designed as a RCT and has been executed in 13 occupational health services. The conduct of the study is guided by a committee of representatives of all professional groups implementing the interventions in the study and by a representative of the grant provider. The most important task of this committee was the critical appraisal of the protocol in the study and the applicability of the interventions during the study. This committee will again be directive in the implementation of results in occupational health practice.

The study design, protocols, procedures and informed consent form were approved by the Medical Ethics Committee of VU University Medical Centre, and all participants provided written, informed consent. All participants were insured according to Dutch Law in case of any damage caused by participation in the study.

\section{Study population}

The source population $(\mathrm{n}=100.000)$ consisted of the population of workers receiving care of the 99 participating OPs. The subjects in this study are on sick leave from regular work for 2 to 6 weeks due to low back pain. Workers have to be in the working age range, that is 18 to 65 years old and are able to understand Dutch in a way that they can give real informed consent and to complete written questionnaires (in Dutch).

The workers have low back pain defined as: pain localised in the lower back without a specific underlying cause, between the lower angle of the scapulae and above the buttocks (ICD-10 codes: M54.5, M54.4, M54.3, M54.1, M54.8 and M54.9). 
The workers' OP informs the researchers whether inclusion in the study is justified on medical grounds. Following the Dutch guideline for low backpain in occupational care [10] patients are excluded in case of specific causes of low back pain: herniated discs with pareses; paralysis; spinal tumour; spinal fracture; ankylosing spondilitis; spinal stenosis; spondylolisthesis; specific rheumatological diseases; pregnancy, in case of serious psychiatric disorders; (ICD-10 code: M51, M51.2, M51.4, M51.3, M51.8, M40M54, M45, M46.0, M46.1, M46.8, M49, and M46.9) or in case of a legal conflict at work, since other interventions are considered more appropriate in these cases. A worker is also excluded if he had been sick-listed due to low back pain less than one month prior to the current episode of sick leave, leaving only new incident cases for our study.

At the start of the study all OPs received additional training from a neurologist in distinguishing between different types of low back pain. In case of doubt the OPs working on the research team (JRA/ WvM) could be consulted.

\section{Sample size}

Workers still on sick leave at 8 weeks are randomized for the Graded Activity intervention. To detect a 30\% difference in recovery rate (return to work) between the Graded Activity group and the usual care group, we need a sample size of 90 workers, resulting in 45 workers in both treatment arms where the second intervention is executed. This difference can be detected with a power (1- $\beta$ ) of $80 \%$ at $\alpha=.05$ [11]. We estimate that $50 \%$ of the population will resume work between 2-8 weeks. Therefore we attempt to enrol 200 workers, resulting in 100 workers per treatment arm for the first intervention, i.e. participatory ergonomics. The sample size of 200 workers is sufficient to detect a $20 \%$ difference in recovery rate (return to work) between the occupational intervention group and usual care. We used our main outcome measure (lasting return to own or equal work) for this sample size calculation. We believe that a $20 \%$ difference in the primary outcome measure is relevant from both the societal as the employers perspective; this difference is statistically significant at $\alpha=.05$ with a power (1- $\beta$ ) of $80 \%$, assuming an intraclass-correlation coefficient of .15 to account for randomisation at OP level.

\section{Treatment allocation}

First randomization took place at the level of the OP, because part of the intervention had to be performed by the occupational physician. Performing one of the interventions during the whole trial reduced the risk of contamination and made performing the interventions easier for the participating OP's. The OP's were stratified before randomisation by economic sectors industry, health care and office work to avoid an unequal distribution in job characteristics after randomization in the treatment groups. A member of our research team (HCWdeV) randomized the OP's, using a series of random numbers.

We randomized the OP's at two different moments. We initially started out with 49 OP's, using a 1:1 ratio for randomization. One year later we were able to recruit 50 more OP's thanks to extra funding from the Dutch government. In the first year we experienced an imbalance in the number of included workers between the two groups, in favour of the intervention OP's. We therefore decided to randomise the second group of OP's using a different ratio. In total 39 OP's were randomized to the intervention group and 60 OP's were randomized to the care as usual group.

If included workers were off work for longer than 8 weeks, they were randomized at the workers level for the second intervention consisting of Graded Activity. An independent examiner (HCWdV) prepared the envelopes for this randomization by coding them according to a list of random numbers.

Fig 1 shows the design of the study.

\section{Blinding}

Obviously, workers, physicians and other therapists can not be blinded for the allocated treatment. Treatment allocation is made known to the worker by the OP after informed consent and completion of the baseline questionnaire. As self-reported outcome measures are used, blinding of most of the outcome measurements during follow up is not possible. We evaluated patients' and physicians' expectations of the effect of the interventions on return-to-work in intervention and control groups to control for the lack of blinding. Since all questionnaires are sent to the worker by mail, no direct influence by the researchers or treating professionals is likely to happen. Similarly, the occupational physician cannot be blinded for treatment. The OP is responsible for providing data on the main outcome: sick leave. The registration of sick leave in the Netherlands is done by companies and managed by the occupational health service. Since these measurements are extracted mainly from automated databases, bias as caused by a lack of blinding is prevented for this outcome measure. The physiotherapists and ergonomists performing the interventions are not involved in performing any of the outcome measures.

\section{Co-interventions and compliance}

Co-interventions could not always be avoided. By informing the patients' GP we tried to minimise co-interventions. In both the intervention and control groups we registered co-interventions by asking the worker and the OP. These data can be used to adjust for co-interventions in the final multivariate analyses. In both the intervention 


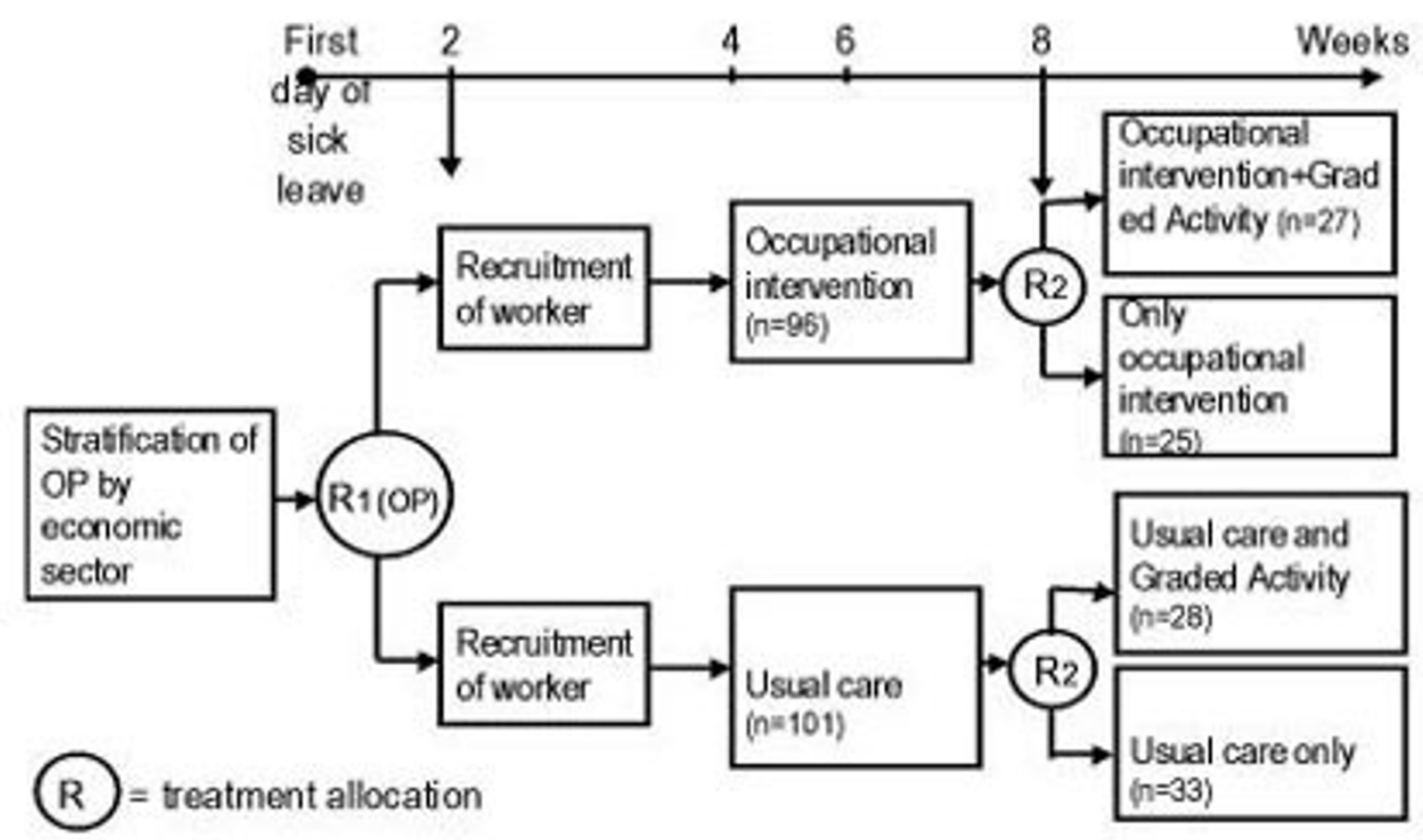

Figure I

Design of study.

and control groups we measured the compliance to the treatment allocation by asking patients, therapists and physicians independently about all interventions applied.

\section{Usual care in the Netherlands OP guideline}

the Dutch occupational guideline on low back pain is an evidence-based guideline. The guideline advocates a visit of the worker to the OP's office at 2 weeks of sick leave due to low back pain. During this visit the OP diagnoses the low back pain. A patient history is made on localisation and radiation of pain, length of the current episode, previous episodes, muscle weakness, loss of sensitivity, miction disorders, general well being, weight loss and fever.

This anamnesis is, if considered appropriate, followed by a physical examination: function of the back and pain induced restrictions, test of Lasègue, the reversed test of Lasègue and tests of the reflexes of the knee and Achilles tendon are being performed.
Based on these findings the OP judges the presence of obstacles for return to work like inadequate sickness behaviour; psychosocial problems; subjective impairments; the effectiveness of curative treatment; working conditions and functional status.

The following interventions are promoted in cases of low back pain without sciatica and of low back pain with mild sciatica without paresis or paralysis:

- Education by the OP referring to: good prognosis and the importance of keeping up or returning to normal activities. The OP emphasises the fact that physical activity does not cause any damage.

- Advise by the OP to return to work within two weeks in the absence of further problems and, if necessary, temporary work adjustments regarding working hours or job content. The workplace is consulted on progress in actions regarding return to work. 
- The general practitioner, or any other medical specialist, is consulted if curative treatment is considered inappropriate. Coping with low back pain, fear of movement and a planning for the resumption of normal activities is discussed with the worker, if considered appropriate.

In the occupational guideline a work place visit by an occupational therapist or ergonomist is optional. The OP guideline is in accordance with the GP guideline and PT guideline on low back pain [12-14]. All guidelines advocate stimulating physical activity and counselling on good prognosis in low back pain in the first 6 weeks of back pain. After 6 weeks exercises or manipulation is considered useful within an active approach.

Description and aim of the Amsterdam Sherbrooke model We replicated the study by Loisel et al[9], after adjustment of the Sherbrooke model for the Dutch situation of occupational health care and disability legislation. In most cases a worker consults his GP first before visiting his occupational physician in case of prolonged sick leave. The general practitioner initiates treatment, if necessary. Curative treatment and waiting lists are considered to be a barrier for return to work in the Netherlands[15]. Because of this, communication between the OP and GP was part of the intervention protocol to try to prevent contradictory advises for the workers and to facilitate return to work. Aim of the entire multi-stage back pain management protocol, and of every component separately, is earlier return to the same work as prior to the present episode of sick leave.

A precise description of the Canadian Sherbrooke model has been published elsewhere[16]. The Amsterdam Sherbrooke model can be divided roughly into two separate interventions. These are described in the following paragraphs.

\section{The occupational intervention}

The first intervention takes place between 2 to 8 weeks of sick leave. The OP, in collaboration with a occupational health nurse or ergonomist, delivered this occupational intervention. The intervention consists of the following steps:

1 Occupational back pain management and work resumption advice by the OP, according to the Dutch OP Guidelines for LBP [10].

2 As an elaboration of the guideline we developed a protocol for communication between the workers OP and the workers GP, to reach consensus on counselling the worker in return to work. Aim was to resolve conflicting approaches by GP and OP, leading to conflicting information to the patient.
A short communication form was developed to inform the GP on the OP's management policy and to gather information on the treatment by the GP [17]. Informed consent has to be given by the employee to obtain this kind of information. The communication form had to be handed over to the GP by the employee.

3 In the occupational guideline a work place visit by an occupational therapist or ergonomist is optional. Because of practical and financial hindrances, the OP seldom makes a referral for such a workplace visit. A participative work adjustment protocol was implemented as a standard intervention in this study. This protocol is carried out by the OHS's ergonomist or Occupational Health nurse. The intervention has been based on methods used in participative ergonomics[18]. We altered existing group based methods to be applied at the level of the individual worker[19]. This method is similar to the method used in Sherbrooke[20].

Every OHS professional in the intervention group was trained in the occupational protocol initially for half a day, with 3-hour feedback sessions over the following 2 years. The ergonomist initiated implementation of the protocol in case of randomization of an eligible worker in the participative work adjustment protocol within one week after the workers' first visit to the OP. Even in case of very early return to work, the protocol was executed to prevent recurrences of sick leave due to low back pain. An extensive description of this protocol was published before[19]. The protocol included the following seven steps:

Step 1. The ergonomist makes an appointment for a meeting with the worker with low back pain, the workers' direct supervisor and possible other stakeholders on the work site. If deemed appropriate the ergonomist collects additional information from the OP.

Step 2. The ergonomist makes an inventory of problems related to back pain based on descriptions from the worker and supervisor. He reaches consensus regarding these problems and prioritises in obstacles for return to work put forward by worker and supervisor.

Step 3. In a brainstorm session, all try to come up with as many solutions as possible to clear the obstacles for return to work. The ergonomist sorts out all the solutions. The ones put forward by the worker and supervisor are seen as most important. All solutions are judged on availability, feasibility and solving capability. Based on these considerations solutions are picked.

Step 4. Preparation for implementation of solutions: the ergonomist, worker and supervisor agree on a plan for 
action. Stakeholders are informed on the actions that they have to take. Responsibility for implementing the solutions is put on the workers' and supervisors' account as much a possible.

Step 5. For implementation of the solutions it may be necessary to give additional instructions or training to the worker at the worksite.

Step 6. One month after step 4 evaluation by the OP takes place with regard to implementation of the solutions agreed upon. Based on this evaluation, fine tuning of the work adjustment may prove to be necessary.

Step 7. The proposed improvements may need further anchoring in the organisation. A stakeholder has to be found for further support of the improvements.

\section{The Graded Activity program}

The second intervention was based on the principles of Graded Activity as developed by Lindström et al $[21,22]$ and adjusted to the Dutch situation. This intervention was implemented by 47 physiotherapists from several in- and out-company training-centres, trained in the Graded Activity protocol. The intervention, adjusted to the Dutch situation, has been evaluated separately at our institute in another randomized clinical trial: the Amsterdam Graded Activity Study [23]. This trial differs from our trial with regard to the level of implementation.

The purpose of the program is to restore occupational function and to facilitate return to work. Primary aim of the program is return to previous work and not pain reduction. All subjects eligible for Graded Activity are sick listed for 8 weeks. During the program the worker is responsible for the results of the therapy. The worker has an active role and the physiotherapist acts as a coach and supervisor, using a hands-off approach [24].

The Graded Activity program consists of the following components:

(1) Patient history and physical examination,

(2) measurement of functional capacity,

(3) an individual, submaximal, gradually increasing exercise program, with an operant-conditioning behavioural approach, based on the results of functional capacity tests, the demands from the patients work and the patients expectations on time to return to work.

Exercise sessions have a frequency of twice a week and last for an hour per session. The first session takes approxi- mately 1.5 hours since a physical examination is part of the first session

The entire program consists maximally of 26 sessions (maximum duration is thus three months). The program should be stopped earlier if a lasting return to own or equal work has been established according to an earlier agreed upon schedule.

In the first session the physiotherapist takes the workers case history. Asking questions on the nature of low back pain (duration, intensity) and on the knowledge of the subject provided by other health care professionals and significant others. Furthermore it is important to know which actions and situations, both private and at work, are troublesome because of low back pain. The physiotherapist asks the worker on his expected date of return to work and the conditions that have to be provided to return to work. This case history should not take more than 5 minutes.

In the first session, the physiotherapist also performs a physical examination to assess range of motion of the spine. In case of radiating pain a short neurological examination should be performed (test of Lasègue or Bragard, knee tendon reflex and/ or Achilles' tendon reflex, sensibility test of the foot). Based on this physical examination, the physiotherapist confirms the diagnosis made by the occupational physician that no abnormalities could be found. Following the examination, the physiotherapist gives counselling on the origin of low back pain, the benign nature and good prognosis of back pain and the patients' own responsibility. This message might take extra effort and repetition in the following sessions.

The remainder of the first session and the following two sessions are used to get a good estimate of the workers functional capacity. The main objective of functional capacity evaluation is reaching a good starting point for therapy. Results on the test are not considered outcome measures in our study protocol. All exercises during the functional capacity evaluation are based on the working to tolerance principle [25]. This testing-phase is pain contingent, which means that the worker may stop if he feels pain or other discomfort.

From the start, the goal of the Graded Activity program is made clear by the physiotherapist: return to work by gradually increasing physical activities. The end of the program is reached as soon as return to regular work is established. The 3 months time limit is not communicated to the worker, because it will probably lead to a time lag. In dialogue, the worker and the therapist reach agreement on the date of return to work. The therapist gently adjusts unreal goals. The OP's expert opinion on return to 
work is being considered in this process. Every other six sessions the progress made and the date for return to work are evaluated.

The Graded Activity program consists of:

1. aerobic exercises on the stationary bike, or rowing machine

\section{2. a step exercise}

3. a lattisimus exercise, the initial weight can either be chosen by the physiotherapist or the worker; 20 to 30 repetitions in a test situation are considered to be an ideal test-result.

4. a dynamic extension exercise: preferably performed on a lower back bench, despite the fact that it might be somewhat frightening to the worker.

5. Abdominal exercise, for instance crunches, or a crossed version of the crunch where the heterolateral knee has to be touched.

6. Getting up from a simple chair, without hand support, possibly making the exercise heavier by holding a (heavy) object.

7/8. Exercises seven and eight are to be designed by the physiotherapist and the worker and should be based on the actions and situations mentioned in the anamnesis. They should simulate the problematic motions of the worker, preferably by simulating working situations.

Some of the exercises can be used as a home assignment. Besides the above mentioned equipment, dumbbells/ free weights and boxes have to be available for simulating working situations.

During the exercise part of the program (i.e. from session 4 onwards) time contingent principles are used, meaning that pain is not a reason for stopping or altering the program, unless a clear relapse (new injury) or deterioration to back pain as mentioned as exclusion criterion in the study population section has taken place. The exercise goals are defined based on the functional capacity evaluation. The starting point of the program is based on $70 \%$ of the mean of all functional capacity test results. The load of each exercise at the end of the program (moment of return to work) is agreed upon at this starting point. The quotas should always be followed exactly, neither underperformed, nor over-performed. The latter might prove difficult for some, especially in the beginning stages of the program. The first quotas are slightly lower than baseline level, to ensure the experience of success ("sure to win").
Successful completion of the quotas should enhance the patients' motivation. Positive reinforcement is a key principle in operant conditioning theory and will be provided by reaching the quotas and by appropriate feedback from the physiotherapist.

In case the physiotherapist finds out that significant others, like partners or co-workers, influence the change in pain behaviour in a negative way, they are invited to attend one or more sessions to gain insight in the rationale of the therapy.

After return to work the worker meets with the physiotherapist for a last time to evaluate the experiences on the work floor.

\section{Outcome assessment}

The first assessment of workers (baseline) is scheduled during the first visit of the OP's office, that is at 2-6 weeks absence from work. There is a 1-year follow-up with assessments at 12 weeks, 26 weeks and 52 weeks after first day of sick leave. In this study records on sick leave were obtained from the occupational health services from the various co-operating companies. Registration of sick leave is a continuous process in occupational health services. It provides reliable data because of commercial interests and double registration at both the companies and the occupational health service. We will choose the occupational health services database since there is a known discrepancy with self reported sick leave [26,27].

\section{Primary outcome measures}

The primary outcome measure in this study is return to work in the year after the first day of sick leave. Since these measurements are gathered from the occupational physicians' records and checked with automated databases blinding is secured.

1) A. Lasting return to own or equal work: duration of work absenteeism due to low back pain in calendar days from the first day of sick leave to full return work in own or other work with equal earnings, for at least 4 weeks without (partial or full) drop-out.

B. Net lasting return to work to own or equal work: net duration of work absenteeism due to low back pain with days of partial return to work converted into number of calendar days of full work absenteeism (net sick leave) from the first day of sick leave to full return work in own or other work with equal earnings, for at least 4 weeks without (partial or full) drop-out. This outcome will be used in all cost-effectiveness analyses.

C. Lasting return to any work: duration of work absenteeism due to low back pain in calendar days from the first 
day of sick leave to (partial or full) return to work for at least 4 weeks, without full drop-out.

2) Total number of days on sick leave due to any condition in the follow up period, since a shift in diagnosis and possible recurrences can be considered as a negative outcome of the interventions.

Return to work is defined in several ways. All definitions are listed in order of importance. Some definitions differ only in detail. The main differences are between lasting return to work and return to work and between time to return to work and the total number of days of sick leave in the year after first day of sick leave (including recurrences). We decided to use a four week period for lasting return to work since a four week period is regarded as a lasting return to work in Dutch occupational care.

De Vet et al [28] pointed out the importance of defining episodes of low back pain in occupational care and suggested the following definition:

- An episode of work absence due to low back pain was defined as a period of work absence due to low back pain, preceded and followed by a period of at least 1 day at work.

This study provides the opportunity to investigate differences in results due to different definitions.

\section{Secondary outcome measures}

In addition, data were collected on:

1. Functional status, using the Roland-Morris Disability24 questionnaire[29]. This questionnaire is widely used in low back pain research and tested as summarised by Riddle[30], as a reaction to Davidson and Keating[31]. There is a valid version of the RDQ-24 available in Dutch [32]. The questionnaire has been adapted for the population in our study (acute and sub-acute low back pain with or without radiating pain). Test retest reliability is considered good over several periods of time [33]: on the same day: $\mathrm{r}=0.91$; after 3 weeks $\mathrm{r}=0.83$; after 6 months $\mathrm{r}=$ 0.72 . Inter-/intrarater reliability is good; $r=0.92$ in 2 raters. Construct-validity is considered good in comparison to several other questionnaires [30]

2. Pain intensity, measured on a 10 point visual analogue scale[34]. This scale consists of three short questions on pain at the moment of filling in the question, the most severe pain in the last week and the mean pain in the last week. All questions are answered on a 10-point scale. The total score is being calculated by taking the summed score of the three items. Test retest reliability of this scale is good with a Cohens' kappa from .66 to .93 [35].
3. Kinesiophobia, fear of incurring (new) physical damage through physical activity, is measured with Tampa Scale for Kinesiophobia[36]. The TSK consists of 17 items. The Dutch version has good reliability and validity[37]. Filling in this questionnaire takes a few minutes. Items are scored on a four point scale from 1 (highly disagree) to 4 (highly agree). The total score is calculated through summed item scores, after reversal of the items four, eight, twelve and sixteen. The total score varies between 17 and 68[38]. If a worker scores higher, than the fear for physical activity or injury is greater. The assumption is that with a high score, physical activity is being avoided. Test-retest reliability in acute low back patients is good with a Pearson's $r=.78$ $(\mathrm{P} \leq .01)$. Internal consistency ranges from alpha $=.70$ to 76 in acute low back patients[38].

4. Fear of movement, avoidance of activities and back pain beliefs are measured with the Fear Avoidance Beliefs Questionnaire $[39,40]$. The FABQ questionnaire consists of two subscales: one regarding physical activity (FABQ/ pa) and one regarding work $(\mathrm{FABQ} / \mathrm{w})$. In acute low back pain patients internal consistency for the FABQ/pa ranged from alpha $=.70$ to .72 and for the $F A B Q / w$ subscale from alpha $=.82$ to .83 . Test-retest reliability in acute low back pain is also good with Pearson's $r=.64$ in the FABQ/pa subscale and .80 in the $\mathrm{FABQ} / \mathrm{w}$ subscale $(\mathrm{P} \leq .01)$.

Concurrent validity between TSK and FABQ is weak to moderately strong, ranging from $r_{\mathrm{s}}=0.33$ to $0.59(P<$ $0.01)$.

5. Patient satisfaction, was measured with the short version of the Patient Satisfaction with Occupational Health Services Questionnaire PSOHQ [41].

6. Coping with pain was measured with the Pain Coping Inventory Scale[42]. The PCI questionnaire measures cognitive and behavioural coping strategies of pain patients. The questionnaire consists of 34 items, scored on a four point scale $(1=$ seldom to never, $2=$ sometimes, $3=$ often and $4=$ very often). The questionnaire consists of six subscales:

\section{1. transformation of pain}

2. distraction

3. lowering demands

4. withdrawal

5. worrying

6. resting 
ad $1 / 2$. Transformation and distraction are considered as cognitive attempts to lead oneself away from pain.

ad 3. Lowering demands: actions aimed at continuing activities despite the pain.

ad 4. Withdrawal: avoiding annoying influences.

ad 5. Worrying; the cognitive component of pain-related fear that shows through unreal expectations and catastrophising thoughts on pain. Worrying can be considered as staying alert for potentially painful stimuli. The flip side of worrying is that it encourages avoiding behaviour like withdrawal and resting, and vice versa.

All coping scales have been proven to be sufficiently reliable and valid. They are sensitive enough to differentiate between coping strategies in pain patients [43].

\section{Prognostic measures}

Information was gathered at baseline on a number of factors that are considered as prognostic factors for sick leave. This enables us to adjust for these factors, in case the randomization fails to divide these variables equally over all groups.

(1) Data on neurological signs, co-morbidity and economical and insurance status of the company are gathered by the treating OP.

(2) Job content data [44,45]are collected at baseline from the worker since the job demands control model could be a predictor for return to work [46].

(3) Data on workload are obtained at baseline using the Dutch Muskuloskeletal Questionnaire[47] as potential confounding variables.

(4) Data on physical activity are gathered at baseline using a sub-scale of the Baecke physical activity questionnaire $[48,49]$.

\section{Cost effectiveness measures}

Cost effectiveness will be evaluated from both the societal perspective and the employers perspective. The workers use of pain medication and use of medical and alternative medical resources is measured at baseline, at 12 weeks, 26 weeks and 52 weeks follow-up, using postal questionnaires, to calculate the direct costs of back pain in both groups. To compare the results of the cost effectiveness analysis with other conditions, general health status is measured according to the standard Dutch version of the EuroQol[50]. Indirect costs are not related to health care but are costs as a consequence of sickness, sick leave, disability and or death of productive persons, in paid and unpaid labour[51]. Since our study takes place in occupational care and since most costs are caused by absenteeism from work [4] we made an extra effort to gather good data on sick leave. Costs of sick leave due to low back pain will be calculated from the net number of days on sick leave and earnings as provided by the employee. In case a participant was reluctant to provide these data a proxy for earnings can be derived from function, age and working hours. The Occupational Health Service provides data on duration of sick leave and of vocational rehabilitation of the worker and the estimated productivity during vocational rehabilitation.

\section{Analysis}

Although we randomized at the OP-level for the first intervention, all analyses will be performed at the patient level. To check the assumption that observations on the OP-level are independent intraclass correlation will be calculated. To examine the success of randomization, descriptive statistics will be used to compare the baseline measurements of the four groups. If necessary, analyses will be adjusted for prognostic dissimilarities. The Cox Proportional hazard model will be used to analyse differences in time until RTW. Student's T-test will be used to analyse differences in total days on sick leave during the year of follow up. Longitudinal multivariate analyses will be used to examine differences in improvement in all secondary outcome measures between the treatment groups.

Indirect costs can be calculated using the friction cost approach (friction period 122 days) and the human capital approach[52] based on income as provided by the worker or as derived from function, age and gender. Boot strapping will be used for pair wise comparison of the mean groups to calculate mean differences and confidence intervals in costs and cost-effectiveness ratios for all interventions. All statistical analyses will be performed according to the intention-to-treat principle. In order to assess whether protocol deviations have caused bias, the results of the intention-to-treat analyses will be compared to per-protocol analyses, including only those employees who complied fully with an intervention protocol.

In case intraclass correlation on the OP-level is > .15, multilevel analysis will be performed to examine the influence of the individual OP.

\section{Discussion}

Our study differs from the study in Canada with respect to the randomization. Because of differences in organisation of occupational care in both countries the first randomization in our study was performed at the level of the participating OP, whereas in the Canadian study randomization took place at the worksite level. The researchers in both studies decided to do so to avoid 
contamination. The second randomization in our study took place in case of sick leave after 8 weeks. In doing so we differ from the design of the Canadian study where randomization took place over four treatment groups at baseline [16]. In our opinion return to work can be slowed down either by the worker or by the OP in case a worker knows that he is allocated to the Graded Activity intervention. This would result in a difference between Graded Activity and control group caused by the design of the study and not by the content of the Graded Activity intervention. Moreover, randomization for Graded Activity at the start of the trial results in a large number of workers (those who have already returned to work) who are not receiving the intervention.

In our cost effectiveness evaluation we did not consider productivity loss due to sickness prior and after the episode of sick leave due to low back pain as proposed by Brouwer et al[53]. Considering productivity loss prior and after the episode of absence could lead to an increase in estimated production losses of about $16 \%$. We have considered productivity loss during vocational rehabilitation. Productivity loss in our opinion is not only influenced by the cause of sick leave but also by the type of work. Some jobs can only be performed in case of full usability. Nurses for instance are called off sick leave only in case they can perform al necessary tasks, in all other cases they are on vocational rehabilitation with a restriction in for instance lifting tasks. Since the start of our study in 1999 a better insight in calculating costs has become available. The availability of instruments for the measurement of productivity losses in recent years can give a better estimate of costs in new research.

Although the interventions have been subject of earlier research, this study provides an international comparison on effectiveness of similar interventions. The results of this RCT will give greater insight to caregivers on treatment options for workers in the sub-acute phase of occupational low back pain. Results might lead to alterations of existing (inter)national guidelines. Furthermore, the results of this RCT will add to the cost-effectiveness of treatment options for workers in the sub-acute phase of occupational low back pain. This study can also provide valuable information to the small body of knowledge from the few studies that focus on effective interventions for return to work in workers on sick leave in the sub-acute phase. Inclusion of workers has stopped in October 2002. First 6 months results of this trial will be available at the end of 2003.

\section{List of abbreviations \\ $\mathrm{OP}=$ occupational physician \\ $\mathrm{GP}=$ general practitioner}

$\mathrm{PT}=$ physiotherapist

$\mathrm{RCT}=$ randomized controlled trial

\section{Competing interests}

None declared.

\section{Authors' contributions}

IAS carried out data collection and drafted the manuscript. JRA participated in data collection. PMB and WvM conceived of the study, and participated in its design and co-ordination. HCWdV resolved statistical and methodological issues. All authors participated in development of research protocols and in the design of the study. All authors read and corrected draft versions of the manuscript and approved the final manuscript.

\section{Acknowledgements}

The authors thank Michel Punte, BA PT, Albére Köke MSc PT, and Bernard Uitdehaag PhD MD for their support in training all OP's and PT's. We would like to thank llse Ürlings for her work in the development of the Participative Ergonomics protocol used in this study and her efforts in training all ergonomists and occupational health nurses in the use of this protocol. We would like to thank Fieke Koopman and the TNO secretary staff for their efforts in obtaining all data. Finally, we would like to thank Patrick Loisel for his advice on the study and his help in recruiting occupational physicians for this study.

This study is granted by: The Netherlands Organisation for Health Research and Development (ZON/Mw), Dutch Ministries of Health, Welfare and Sports and, of Social Affairs

\section{References}

I. Staal JB, Hlobil H, van Tulder MW, Köke AJA, Smid T, van Mechelen W: Return-to-work interventions for low back pain - A descriptive review of contents and concepts of working mechanisms. Sports Medicine 2002, 32:25I-267.

2. Egger M, Smith GD, Sterne JA: Uses and abuses of meta-analysis. Clin Med 200I, I:478-84.

3. Easterbrook PJ, Berlin JA, Gopalan R, Matthews DR: Publication bias in clinical research. Lancet I991, 337:867-72.

4. van Tulder MW, Koes BW, Bouter LM: A cost-of-illness study of back pain in The Netherlands. Pain 1995, 62:233-40.

5. Hutubessy RC, van Tulder MW, Vondeling H, Bouter LM: Indirect costs of back pain in the Netherlands: a comparison of the human capital method with the friction cost method. Pain 1999, 80(I-2):20I-7.

6. Lee P: The economic impact of musculoskeletal disorders. Qual Life Res 1994, 3 SuppI I:S85-S9I.

7. Abenhaim L, Suissa S: Importance and economic burden of occupational back pain: a study of 2,500 cases representative of Quebec. J Occup Med 1987, 29:670-4.

8. Scientific approach to the assessment and management of activity-related spinal disorders. A monograph for clinicians. Report of the Quebec Task Force on Spinal Disorders. Spine 1987, I 2: I-59.

9. Loisel P, Abenhaim L, Durand P, Esdaile JM, Suissa S, Gosselin L, Simard R, Turcotte J, Lemaire J: A population-based, randomized clinical trial on back pain management. Spine 1997, 22:29II-8.

10. NVAB: Handelen van de bedrijfsarts bij werknemers met lage rugklachten. 1999.

II. Pocock SJ: Clinical trials, a practical approach Great Brittain, John Wiley \& Sons Ltd.; 1987.

12. Faas A, Chavannes AW, Koes BW: NHG-Standaard Lage Rugpijn (Dutch GP guideline on low back pain). Huisarts Wet 1996, 39:|8-3|. 
13. Bekkering GE, Hendriks HJM, Koes BW, Oostendorp RAB, Ostelo RWJG, Thomassen JMC: Dutch physiotherapy guidelines for low back pain. Physiotherapy 2003, 89:29। I-2918.

14. Koes BW, van Tulder MW, Ostelo R, A.K. Burton, Waddell G: Clinical guidelines for the management of low back pain in primary care: an international comparison. Spine 200I, 26:2504-25I3

15. Anema JR, Van Der Giezen AM, Buijs PC, van Mechelen W: Ineffective disability management by doctors is an obstacle for return-to-work: a cohort study on low back pain patients sicklisted for 3-4 months. Occup Environ Med 2002, 59:729-33.

16. Loisel P, Durand P, Abenhaim L, Gosselin L, Simard R, Turcotte I, Esdaile JM: Management of occupational back pain: the Sherbrooke model. Results of a pilot and feasibility study. Occup Environ Med 1994, 5 I:597-602.

17. Anema JR, Buijs PC, van Putten DJ: Samenwerking van huisarts en bedrijfsarts : een leidraad voor de praktijk. Medisch contact 200I, 56:790-793.

18. de Jong AM, Vink P: Participatory ergonomics applied in installation work. Appl Ergon 2002, 33:439-48.

19. Anema JR, Steenstra IA, Urlings IJM, Bongers PM, de Vroome EMM, van Mechelen W: Participatory Ergonomics as a Return-toWork Intervention; a future challenge? Am J Ind Med 2003, 44:273-28I.

20. Loisel P, Gosselin L, Durand P, Lemaire J, Poitras S, Abenhaim L: Implementation of a participatory ergonomics program in the rehabilitation of workers suffering from subacute back pain. Appl Ergon 200I, 32:53-60.

2I. Lindstrom I, Ohlund C, Eek C, Wallin L, Peterson LE, Fordyce WE, Nachemson $A L$ : The effect of graded activity on patients with subacute low back pain: a randomized prospective clinica study with an operant-conditioning behavioral approach. Phys Ther 1992, 72:279-290.

22. Lindstrom I, Ohlund C, Nachemson A: Physical performance, pain, pain behavior and subjective disability in patients with subacute low back pain. Scand J Rehabil Med 1995, 27:153-160.

23. Staal JB, Hlobil H, Twisk JWR, Smid T, van Mechelen W: The effects of graded activity for low back pain in occupational health on absence from work, functional status and pain. Annals of Intern Med 2003 in press.

24. Köke AJA, Thomassen JMC: Operante behandelingsstrategieën. Gedragsgeoriënteerde behandelingsstrategieën bij rugpijn. Cure en care development.; 2000

25. Fordyce WE: Behavioral methods for chroninc pain and illness. St. Louis : Mosby 1976.

26. Dasinger LK, Krause N, Deegan LJ, Brand RJ, Rudolph L: Duration of work disability after low back injury: a comparison of administrative and self-reported outcomes. Am J Ind Med 1999 , 35:6|9-3|

27. van Poppel MN, de Vet HC, Koes BW, Smid T, Bouter LM: Measuring sick leave: a comparison of self-reported data on sick leave and data from company records. Occup Med (Lond) 2002, 52:485-90.

28. de Vet HC, Heymans MW, Dunn KM, Pope DP, van der Beek AJ, Macfarlane GJ et al:: Episodes of low back pain: a proposal for uniform definitions to be used in research. Spine 2002 27:2409-24l6

29. Roland M, Morris R: A study of the natural history of back pain. Part I: development of a reliable and sensitive measure of disability in low-back pain. Spine 1983, 8: |4|-4.

30. Riddle DL, Stratford PW: Roland-Morris scale reliability. Phys Ther 2002, 82:512-5

31. Davidson M, Keating JL: A comparison of five low back disability questionnaires: reliability and responsiveness. Phys Ther 2002, 82:8-24.

32. Gommans IHB, Koes BW, van Tulder MW: Validiteit en responsiviteit Nederlandstalige Roland Disability Questionnaire. Vragenlijst naar functionele status bij patiënten met lage rugpijn. Nederlands Tijdschrift voor Fysiotherapie 1997, 2:28-33.

33. Stratford PW, Binkley J, Solomon P, Gill C, Finch E: Assessing change over time in patients with low back pain. Phys Ther 1994, 74:528-33.

34. Carlsson AM: Assessment of chronic pain. I. Aspects of the reliability and validity of the visual analogue scale. Pain 1983, 16:87-101.
35. Roach KE, Brown MD, Dunigan KM, Kusek CL, Walas M: Testretest reliability of patient reports of low back pain. J Orthop Sports Phys Ther 1997, 26:253-9.

36. Miller RP, Kori SH, Todd DD: The Tampa Scale. 1991.

37. Goubert L, Crombez G, Vlaeyen JWS, Van Damme S, Van den Broeck A, Van Houdenhove B.: De Tampa schaal voor kinesiofobie. Psychometrische karakteristieken en normering. Gedrag en Gezondheid 2000, 28:54-62

38. Swinkels-Meewisse EJCM, Swinkels RAHM, Verbeek ALM, Vlaeyen JWS, Oostendorp RAB: Psychometric properties of the Tampa Scale for kinesiophobia and the fear-avoidance beliefs questionnaire in acute low back pain. Manual Therapy 2003, 8:29-36.

39. Waddell G, Newton M, Henderson I, Somerville D, Main CJ: A FearAvoidance Beliefs Questionnaire (FABQ) and the role of fear-avoidance beliefs in chronic low back pain and disability. Pain 1993, 52: 157-68.

40. Philips HC: Avoidance behaviour and its role in sustaining chronic pain. Behav Res Ther 1987, 25:273-9.

4I. Verbeek JHAM, de Boer AG, van der Weide WE, Piirainen H, Anema JR, van Amstel $R$, Hartog F: Patient satisfaction with occupational health services, development of a questionnaire. 2003.

42. Kraaimaat FW, Bakker AH, Evers AWM: Pain Coping Strategies in chronic pain patients: the development of the Pain-Coping-Inventory list [In Dutch: Pijncoping-strategieeen bij chronische pijnpatienten: de ontwikkeling van de Pijn-Coping-Inventarisatielijst]. Gedragstherapie 1997, 30:I85-20I.

43. Kraaimaat FW, Bakker AH: Pain coping strategies in chronic pain patients: The development of The Pain Coping Inventory (PCI). 1994.

44. Karasek R: Job Content Instrument Users Guide: revision I.I. 1985.

45. Karasek R, Brisson C, Kawakami N, Houtman I, Bongers PM, Amick B: The Job Content Questionnaire (JCQ): an instrument for internationally comparative assessments of psychosocial job characteristics. J Occup Health Psychol 1998, 3:322-55.

46. Janssen N, van den Heuvel WP, Beurskens AJ, Nijhuis FJ, Schroer CA van Eijk JT: The Demand-Control-Support model as a predictor of return to work. Int J Rehabil Res 2003, 26: I-9.

47. Hildebrandt VH, Bongers PM, van Dijk FJ, Kemper HC, Dul J: Dutch Musculoskeletal Questionnaire: description and basic qualities. Ergonomics 200।, 44: I038-55.

48. Baecke JA, Burema J, Frijters JE: A short questionnaire for the measurement of habitual physical activity in epidemiological studies. Am J Clin Nutr 1982, 36:936-42.

49. Pols MA, Peeters PH, Bueno-De-Mesquita HB, Ocke MC Wentink $\mathrm{CA}$, Kemper $\mathrm{HC}$, Collette $\mathrm{HJ}$ : Validity and repeatability of a modified Baecke questionnaire on physical activity. Int Epidemiol 1995, 24:38|-8.

50. Dolan P: Modeling valuations for EuroQol health states. Med Care 1997, 35:1095-108.

51. Brouwer WB, Koopmanschap MA, Rutten FF: Patient and informal caregiver time in costeffectiveness analysis. A response to the recommendations of the Washington Panel. Int J Technol Assess Health Care 1998, I4:505-5I3

52. Oostenbrink JB, Koopmanschap MA, Rutten FF: Standardisation of costs: the Dutch Manual for Costing in economic evaluations. Pharmacoeconomics 2002, 20:443-454.

53. Brouwer WB, van Exel NJ, Koopmanschap MA, Rutten FF: Productivity costs before and after absence from work: as important as common? Health Policy 2002, 61 : 173-87.

\section{Pre-publication history}

The pre-publication history for this paper can be accessed here:

http://www.biomedcentral.com/1471-2474/4/26/prepub 